Original Research Paper

\title{
Numerical Simulation of Liquid Bio-Fuel Combustion in an EGR Equipped Micro Gas Turbine
}

\author{
${ }^{1}$ Maria Cristina Cameretti, ${ }^{2}$ Raffaele Tuccillo, ${ }^{3}$ Fabrizio Reale and ${ }^{4}$ Renzo Piazzesi \\ ${ }^{1,2}$ Department of Industrial Engineering (D.I.I), Università di Napoli Federico II, Napoli, Italy \\ ${ }^{3}$ Istituto Motori, National Research Council (C.N.R.), Napoli, Italy \\ ${ }^{4}$ ANSYS UK Ltd., Abingdon, UK
}

Article history

Received: 10-10-2014

Revised: 07-04-2015

Accepted: 22-05-2015

Corresponding Author:

Raffaele Tuccillo

Department of Industrial

Engineering (D.I.I), Università di

Napoli Federico II, Napoli, Italy

Email: raffaele.tuccillo@unina.it

\begin{abstract}
This paper focuses the attention to the possibility of a correct combustion close to the flameless regime, even in the presence of lower calorific value fuels like those that can be found with high concentrations in the bio-mass derived ones. In addition, the authors pay attention to the nitric oxide control by means of an optimal choice of the pilot injector location. The authors follow their previous experiences in the search of feasible modifications to an existing lean-premixed combustor for a definite pollutant abatement from a micro-gas turbine.
\end{abstract}

Keywords: Micro Gas Turbines, Flameless Combustion, Bio-Fuels

\section{Introduction}

In their papers (Cameretti et al., 2006; 2007; 2008; 2009; 2010; Cameretti and Tuccillo, 2014; Cameretti et al., 2013) the authors have developed a comprehensive investigation of several aspects concerning the flameless concept for reduced nitric oxide emissions from micro gas turbines. As well known, activating an exhaust recirculation at the compressor inlet (Camporeale and Fortunato, 2007) allows the combustion chamber to be entered by an air-gas mixture with a relevant oxygen defect. Such a condition, together with the high temperature level induced by the recuperated cycles, leads the combustion development to situations close to the so called MILD (Cavaliere and de Joannon, 2004) or flameless (Panne et al., 2009; Duwig et al., 2006; Levy et al., 2007a; Li et al., 2006) regime. The authors have highlighted the advantages that arise from the adoption of an external EGR system, together a number of limitations, say:

- A performance decay that derives from the decreased compressor flow capacity and pressure ratio, as a consequence of the exhaust-air mixing

- The increase in carbon monoxide and unburned species emissions that result from the smoother combustion regime

In their most recent papers (Cameretti et al., 2009; 2010; Cameretti and Tuccillo, 2014; Cameretti et al., 2013) the authors have demonstrated that the above problems may be partly overcome by simple, low-cost, modifications to the combustor assembly, like a different location of the pilot injector. This solution, once the optimal location has been determined, allows activation of the reactant ignition in a zone with a relevant presence of inert species, so inhibiting the thermal $\mathrm{NO}_{\mathrm{x}}$ formation (Dagaut and Cong, 2007; Levy et al., 2007b; 2009).

Both solutions are of particular interest at part load operation, because of the increased fuel flow rate that is addressed to the pilot line. In some cases, the combined employment of the modified pilot location with a limited EGR rate allows to approach emission free combustion regimes when supplying the chamber with natural gas or kerosene.

Basing on the above encouraging experiences, the authors examine in this study the off-design conditions that are induced in the combustor by non conventional fuels, like those of the bio-fuel category (Li et al., 2010; Glaude et al., 2010; Crayford et al., 2010; Moliere et al., 2009; Bolszo et al., 2007; Baessler et al., 2006; Cameretti and Tuccillo, 2014). Actually, the different fuel composition and the changes in fuel/air ratios that are needed for reaching the rated conditions could induce an off-design behaviour of the combustor with a consequent increase in $\mathrm{NO}_{\mathrm{x}}$ emission. So, the same analysis as the one carried out for conventional fuels is worthy of refinement in order to get validation from a wider range of fuelling conditions.

The numerical techniques combine a matching analysis of the whole system with a CFD simulation 
of the combustor and both conventional and bio-fuels are considered. The main attention is paid to liquid fuels, because of the renewed interest in their employment in gas turbines (Moliere et al., 2010; Andrews et al., 2007; Nakamura et al., 2006; Cameretti et al., 2013). The aim is to find the optimal combination of the EGR rates and pilot injector location for minimizing the emissions in a wide range of the micro gas turbine operation.

\section{The Comparison of Internal and External EGR}

\section{The External EGR Option}

In the recent authors' papers (Cameretti et al., 2006; 2007; 2008; 2009; 2010), a detailed description of the modified layout of the $110 \mathrm{~kW}$ micro-gas turbine can be found: In particular The Exhaust Recirculation (EGR) circuit (Fig. 1) allows dilution of air with a fraction of the residual gases, while the recuperator by-pass option is helpful for adapting the $M G T$ operation to different electrical and thermal power demands. Consequently, the constant speed operation of the system is basically governed by the parameters.

Recuperator by-pass ratio:

$$
X_{b}=1-\frac{\dot{m}_{g}, R}{\dot{m}_{g}}
$$

\section{EGR ratio:}

$$
X_{e g r}=\frac{\dot{m}_{e g r}}{\left(1-X_{b}\right) \dot{m}_{g}}
$$

The proposal of the EGR concept as applied to the micro-gas turbine layout originates from the attempt of achieving combustion regimes close to those recognizable as MILD or flameless ones. Actually, the oxygen defect in the oxidant together with the high combustor entry temperature that results from the recuperated cycles generate conditions that allow a fair approximation of the MILD combustion regime (Cameretti et al., 2006; Camporeale and Fortunato, 2007; Cavaliere and de Joannon, 2004) with much smoother temperature profiles.

More generally, both parameters in Equation 1 and 2 affect the oxidant temperature and composition at the combustor inlet and, therefore, the combustion development together with the pollutant formation and with the actual mass flow rate of exhausts to be mixed with the external air as well. In this sense, such a system can be identified as an "external EGR" option, since it directly modifies the thermodynamic and chemical characteristics of the working fluid through the power plant components.

The previous authors' papers have also evidenced that, in despite of the after cooling of the mixed species, the temperature increase at the compressor inlet induces a penalty in the thermal cycle, since it induces limitations in the compressor flow capacity and a compression work increase.

In Fig. 2, a typical trade-off between the benefits and the disadvantages of the external EGR adoption is clearly displayed, in the case of constant speed, full load operation with the two different liquid fuels that were examined in detail in the following sections. The curves in this figure result from an integrated analysis based on the component matching and the thermokinetic modelling of the combustion process (Cameretti et al., 2006; 2007).

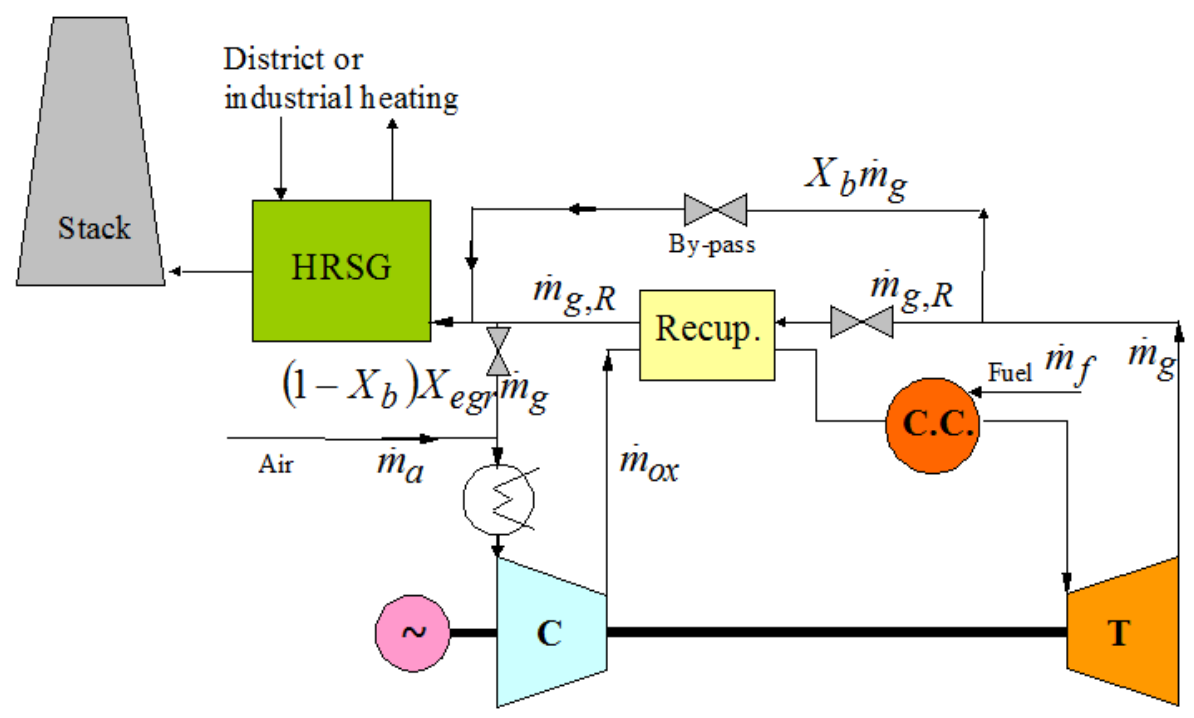

Fig. 1. Plant layout of the recuperated micro-gas turbine with the exhaust recirculation option 


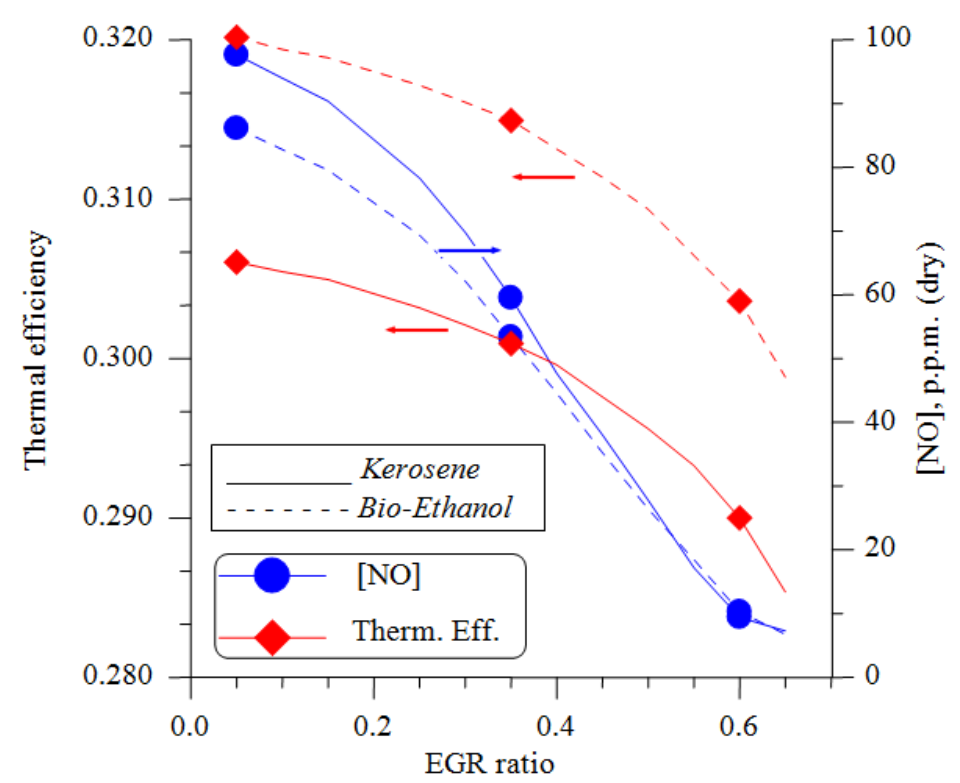

Fig. 2. The EGR effect on MGT efficiency and emissions (full load, fully recuperated cycles)

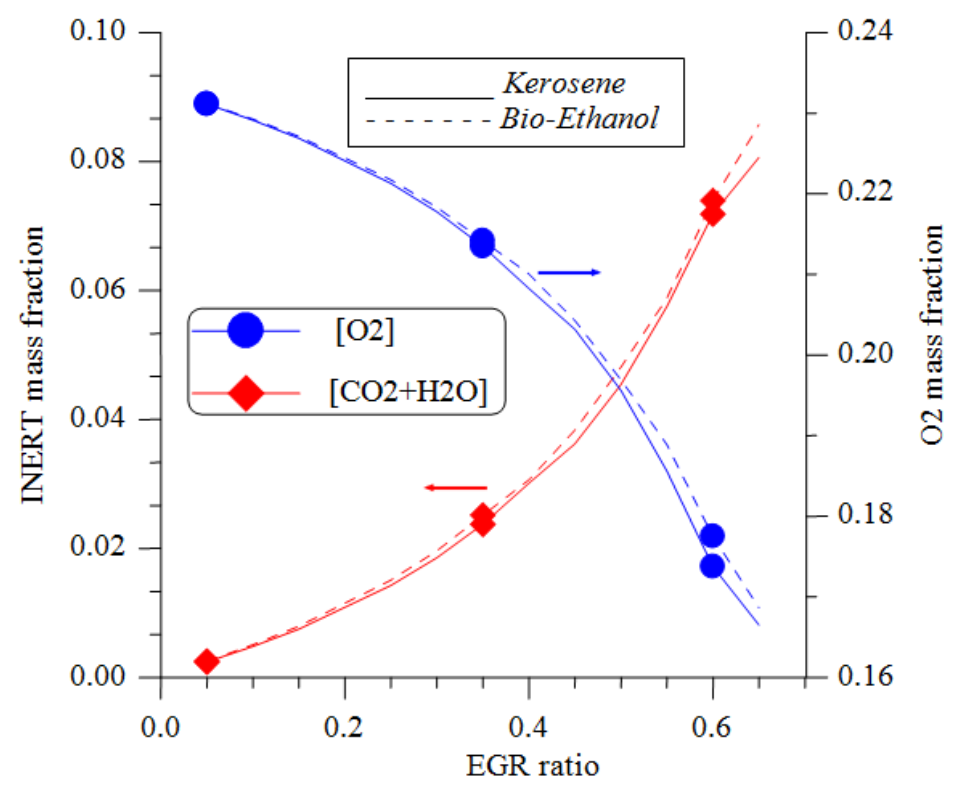

Fig. 3. The EGR effect on the oxidant composition

The approach is sensitive on the oxidant composition, whose variation with the EGR rate is displayed in Fig. 3. To the sake of conciseness, such an analysis is not discussed in this study and it could be repeated also for variable speed operation and for different levels of the recuperator by-pass ratio. Some key aspects can be underlined:

- The external EGR allows the zero $\mathrm{NO}_{\mathrm{x}}$ emissions to be approached only if the recirculation ratio $X_{e g r}$ is greater than 0.6 , so leading to a non negligible performance decay of the micro-gas turbine
- For natural gas fuelling the benefits are more evident at part-load (Cameretti et al., 2006; 2007; 2008; 2009), as a direct consequence of the leanpremixed operation that requires increased fuel rates to the pilot line when the overall equivalence ratio is reduced. In the case of liquid fuels, noticeable advantages appear to be achievable also at full load (Fig. 2)

- The ethanol composition, that approximates the bio-fuel examined in this study, seems to be favourable both in terms of thermal efficiency and 
thermal NO reduction (Fig. 2). Such a consideration encourages the development of a combustion analysis either with pure bio-fuel or with fossil and bio fuels mixtures

\section{The Internal EGR}

The previous authors' papers (Cameretti et al., 2009; 2010) have demonstrated that, at least at full load operation, the exhaust recirculation option in Fig. 1 may be successfully replaced by a simpler, more efficient solution that founds on a different location of the pilot injector within the $L P$ or $L P P$ combustor. Such a solution represents therefore a low-cost modification for the pollutant abatement from existing micro-gas turbine combustors.

Figures 4 to 6 display a sketch of the lean-premixed tubular combustor (Russo et al., 2007; Cameretti et al., 2013) and the two-dimensional and 3D domains that have been set up for the CFD simulations. The latter exhibits, of course, a more detailed insight into the general flow field and in the fuel-air mixing process (Cameretti et al., 2009), but a fair approximation is obtainable with the 2D simulations with more affordable computational costs. The blockquadrilateral mesh is of nearly 45000 cells with grid refinements in the fuel injection and reactant mixing regions (Fig. 5). Also the 3D (Fig. 6) domain is meshed with a block structured grid of 350000 cells and it also includes the air inlet upstream of the flow split between the main stream and the external liner. In addition, the air flow through the swirling vanes is included in the computations, so that the resulting swirl ratio is automatically predicted.

The same Fig. 5 displays the original location of the pilot injectors together with the alternate ones that have been experienced in the authors' work (Cameretti et al.,
2010). As stated before, this proposal arises from the consideration that the flameless regime may be also approached if the combustion is activated in regions that are characterized by poor oxygen contents and by the presence of combustion products (Cameretti et al., 2009; 2010; Levy et al., 2007b; 2009) Therefore, shifting the pilot line to one of the positions in Fig. 5 aims at injecting the fuel within a region with an high vorticity flow pattern (Fig. 6) that is induced by the main swirled stream from the premixing line.

The counter-rotating vortices (Fig. 7) partially recirculate the combustion products and allow transport and mixing of the gases from the end-wall zones with the main reacting flow. The fuel jet meets therefore an oxidant with reduced oxygen contents, due to the internal recirculation of a portion of the flue gases. The simultaneous presence of inert species in this region contributes to temperature peak reduction and therefore to a substantial limitation of the nitric oxide formation rate.

On the other hand, the optimal injector location should also preserve the combustor walls from an excess in gas temperature. The best compromise that must be found between these conflicting occurrences seems to be the modified pilot location \#3 in Fig. 5 and 6, both for gaseous and liquid fuel supply (Cameretti et al., 2010). In the same paper the effectiveness of this solution is widely demonstrated when full load conditions are considered, while at part load a satisfactory $\mathrm{NO}_{\mathrm{x}}$ control requires the simultaneous activation of the external EGR. Also in this case, the choice of the new location of the pilot injector is favourable since it allows a reduced $E G R$ rate and therefore the thermal efficiency decay becomes less dramatic.

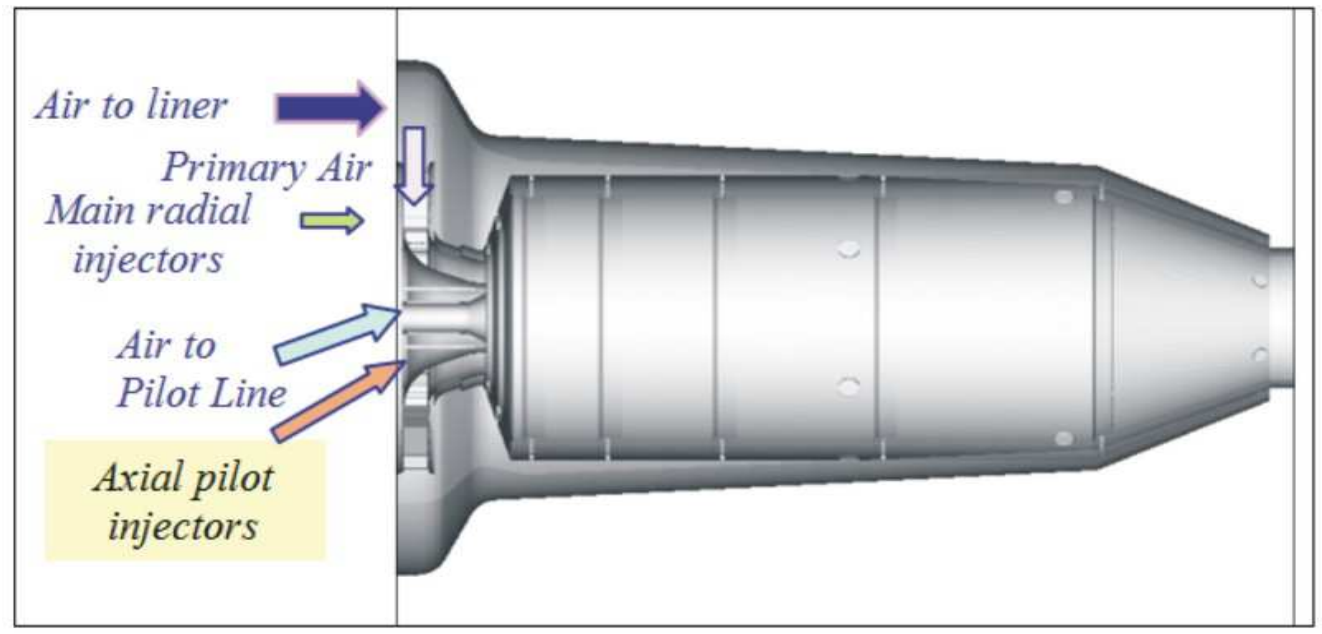

Fig. 4. The lean premixed combustor 


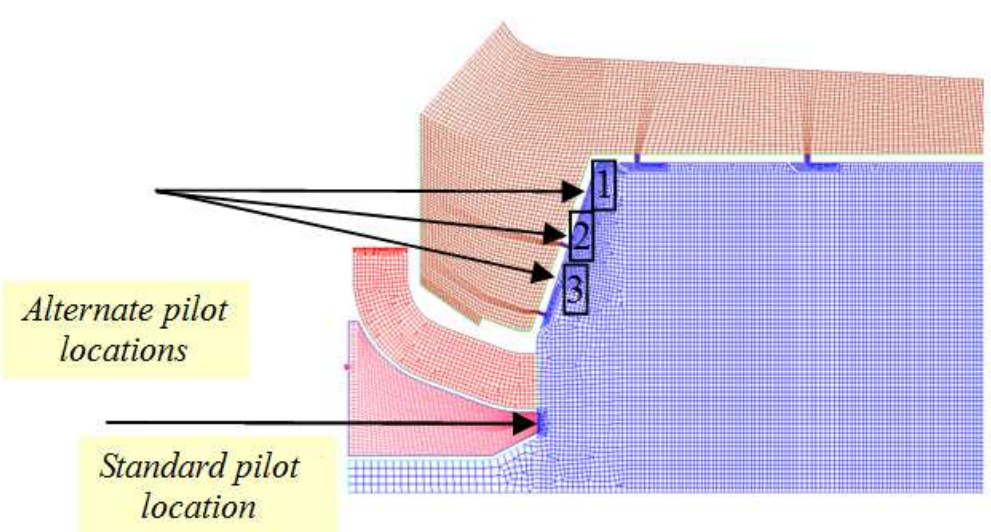

Fig. 5. 2D domain and block-quadrilateral mesh

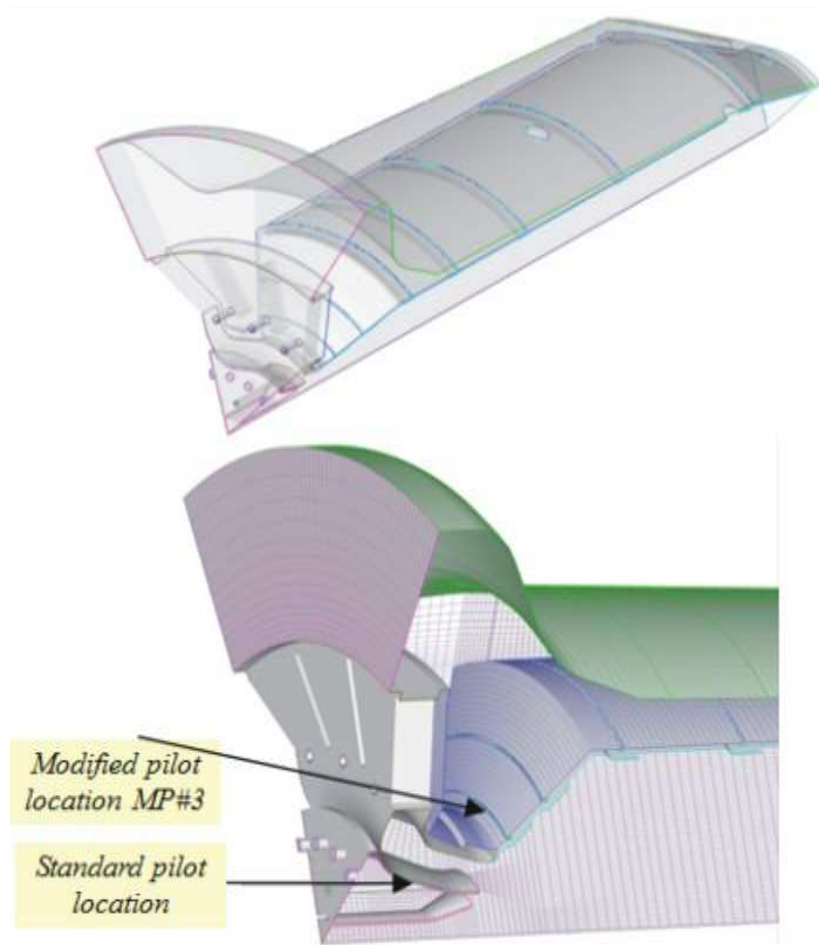

Fig. 6. 3D domain and block-structured mesh

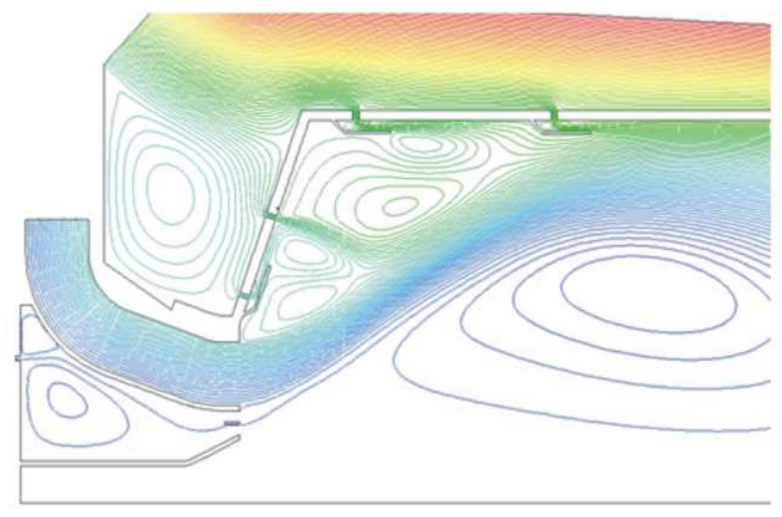

Fig. 7. Streamlines and vortex pattern in the primary region
Such encouraging experiences, together with the preliminary results in Fig. 2, suggested the authors to extend their study to the combustion analysis of biofuels, in particular of the liquid type, as discussed in the following section.

\section{The CFD Simulation of the Liquid Fuelling Cases}

The cases with the liquid fuel supply aim at the comparison of the combustion development and pollutant formation induced by a conventional fuel like the kerosene and a product of renewable sources like the bio-ethanol (Glaude et al., 2010; Moliere et al., 2010; 
Crayford et al., 2010); in addition the possibility of supplying the main $L P P$ line with bio-ethanol and the pilot injector with kerosene was considered. As well known, the bio-ethanol represents a widely diffused component in liquid fuel mixtures obtained by the biomass treatment (Glaude et al., 2010). In the following, the pure ethanol fuelling is considered in order to establish a baseline level of comparison with the employment of conventional fuels. The additional option of the mixed fuel supply would be helpful in some particular operating conditions like at part-load or during the start-up and shutdown of the micro-gas turbine.

The main properties of the liquid fuels are summarized in Table 1, which puts into evidence the main parameters that affect the fundamental processes, like the droplet atomization and the reactant mixture quality in the different regions of the chamber. The air and fuel flow rate data refer to the base rating operation that implies a firing temperature of nearly $1220 \mathrm{~K}$ at 3.8 bar.

The authors' papers (Cameretti et al., 2006; 2007; $2008 ; 2009$; 2010) provide a detailed description of the numerical simulation set up for the analysis of the flow and thermo chemical processes inside the tubular combustor of the micro-turbine. Therefore, only the most significant aspects are here recalled:

- The FLUENT ${ }^{\circledR}$ code is addressed to the analysis of both 2D, axisymmetric and fully 3D domains. The turbulent flow solution founds on the standard $\mathrm{k}-\varepsilon$ model

- The reacting, multiphase flow simulation includes the prediction of the droplet atomization process with the $T A B$ model

- The final rate-eddy dissipation concept (Magnussen and Hjertager, 1977) is adopted for the fuel oxidation. The kinetic mechanisms is based on the following scheme:

$$
\begin{aligned}
& \text { 1) } \mathrm{C}_{12} \mathrm{H}_{23}+17.75 \mathrm{O}_{2} \Rightarrow 12 \mathrm{CO}_{2}+11.5 \mathrm{H}_{2} \mathrm{O} \\
& R_{1}=2.587 * 10^{9}\left[\mathrm{C}_{12} \mathrm{H}_{23}\right]^{0.25}\left[\mathrm{O}_{2}\right]^{1.5} e^{-\frac{1.256^{* 10^{8}}}{T}} \\
& \text { 2) } \mathrm{C}_{2} \mathrm{H}_{5} \mathrm{OH}+3 \mathrm{O}_{2} \Rightarrow 2 \mathrm{CO}_{2}+3 \mathrm{H}_{2} \mathrm{O} \\
& R_{2}=8.435 * 10^{9}\left[\mathrm{C}_{2} \mathrm{H}_{5} \mathrm{OH}\right]^{0.15}\left[\mathrm{O}_{2}\right]^{1.6} e^{-\frac{1.256^{*} * 0^{8}}{T}} \\
& \text { 3) } \mathrm{CO}_{2} \Rightarrow \mathrm{CO}+1 / 2 \mathrm{O}_{2} \\
& R_{3}=5 * 10^{8}\left[\mathrm{CO}_{2}\right]\left[\mathrm{O}_{2}\right]^{0.25} e^{-\frac{1.7 * 10^{8}}{T}} \\
& \text { 4) } \mathrm{CO}+\frac{1}{2} \mathrm{O}_{2} \Rightarrow \mathrm{CO}_{2} \\
& R_{4}=2.239 * 10^{12}[\mathrm{CO}]\left[\mathrm{O}_{2}\right]^{0.25} e^{-\frac{1.674^{*} 0^{8}}{T}}
\end{aligned}
$$

- The inlet and boundary conditions (i.e., mass flow rates and temperatures), together with the combustor outlet pressure, are derived from a preliminary thermodynamic analysis of the system

- For each type of fuel supply, the calculations refer to both the standard and the modified pilot location

- An initial droplet diameter of $50 \mu \mathrm{m}$ was assumed for both main and pilot injection, with a velocity of the liquid phase of $30 \mathrm{~m} / \mathrm{s}$

Table 2 and 3 provide an immediate overview of the results of the $C F D$ based simulations in a twodimensional domain. Basically, such tables give a further confirmation of the advantages that can be derived from an appropriate choice of the pilot injector location. Actually, in all the cases examined the modified pilot location leads to a noticeable reduction of the nitric oxides, without affecting the combustion efficiency, Actually, the combustor exit temperatures are left practically unchanged when shifting the pilot location and no relevant increase is observed in carbon monoxide and unburned hydrocarbons.

Table 1. Kerosene and ethanol data employed for the MGT combustion simulation

\begin{tabular}{llc} 
Table 1. Kerosene and ethanol data employed for the MGT combustion simulation & \\
\hline & Base rating, Fully recuperated cycle $(X b=0)$ & Ethanol \\
\hline LHV, kJ/kg & Kerosene & 27500 \\
$\mathrm{fSt}_{\mathrm{St}}$ & 43124 & 0.0957 \\
$(\mathrm{OFR}) \mathrm{st}$ & 0.0685 & 2.435 \\
Dynamic viscosity, $\mathrm{kg} /(\mathrm{ms})$ & 3.401 & 0.0012 \\
Surface Tension, N/m & 0.0024 & 0.0223 \\
Vaporiz. Temp. (1.013bar), K & 0.0263 & 341 \\
Combustor Inlet Temp. & 271 & $905 \mathrm{~K}$ \\
Oxidant mass flow rate & $905 \mathrm{~K}$ & $0.808 \mathrm{~kg} / \mathrm{s}$ \\
Fuel mass flow rate & $0.808 \mathrm{~kg} / \mathrm{s}$ & $0.00650 \mathrm{~kg} / \mathrm{s}$ \\
Fuel \% to pilot & $0.00756 \mathrm{~kg} / \mathrm{s}$ & $10 \%$ \\
Overall equiv. ratio & $10 \%$ & 0.148 \\
LPP line equiv. ratio & 0.137 & 0.484 \\
Pilot line equiv. ratio & 0.445 & 1.280
\end{tabular}


Maria Cristina Cameretti et al. / American Journal of Applied Sciences 2015, 12 (7): 463.478 DOI: 10.3844/ajassp.2015.463.478

Table 2. Volume averaged and outlet properties from CFD based simulations

\begin{tabular}{|c|c|c|c|c|c|c|}
\hline \multirow[b]{2}{*}{ Fuel/Pilot } & \multicolumn{2}{|l|}{ Volume } & \multicolumn{4}{|c|}{ Outlet } \\
\hline & {$\left[\bar{O}_{2}\right], \%, \mathrm{~mol}$} & $\mathrm{~T}_{\max }, \mathrm{K}$ & $\mathrm{T}, \mathrm{K}$ & [NO], p.p.m. & [CO], p.p.m. & [UHC], p.p.m. \\
\hline Kerosene/Standard & 17.38 & 2758 & 1233 & 197.0 & 61 & $1.0 \times 10^{-3}$ \\
\hline Kerosene/MP \#3 & 17.62 & 1941 & 1233 & 18.0 & 57 & $6.1 \times 10^{-4}$ \\
\hline Bio-ethanol/Standard & 17.64 & 2629 & 1211 & 68.0 & 34 & $4.5 \times 10^{-1}$ \\
\hline Bio-ethanol/MP \#3 & 17.88 & 1806 & 1210 & 1.9 & 30 & $4.5 \times 10^{-1}$ \\
\hline Bio-eth. + ker./Standard & 17.57 & 2712 & 1214 & 128.0 & 37 & $5.7 \times 10^{-3}$ \\
\hline Bio-eth + ker. /MP \#3 & 17.81 & 1815 & 1214 & 6.0 & 34 & $2.3 \times 10^{-3}$ \\
\hline
\end{tabular}

Table 3. Volume-averaged and maximum of reaction and nitric oxides rates

\begin{tabular}{llll}
\hline Fuel/Pilot & Value & $\begin{array}{l}\text { Thermal NO } \\
\text { rate, } \mathrm{kmole} /\left(\mathrm{m}^{3} \mathrm{~s}\right)\end{array}$ & $\begin{array}{l}\text { Fuel oxidation } \\
\text { rate, } \mathrm{kmole} /\left(\mathrm{m}^{3} \mathrm{~s}\right)\end{array}$ \\
\hline Kerosene/Standard & Average & $6.11 \times 10^{-4}$ & $5.00 \times 10^{-3}$ \\
& Maximum & $4.52 \times 10^{-1}$ & 1.423 \\
Kerosene/MP \#3 & Average & $1.77 \times 10^{-6}$ & $5.04 \times 10^{-3}$ \\
& Maximum & $3.93 \times 10^{-5}$ & 1.134 \\
Bio-ethanol/Standard & Average & $2.07 \times 10^{-4}$ & $2.75 \times 10^{-2}$ \\
& Maximum & $1.16 \times 10^{-1}$ & 8.133 \\
Bio-ethanol /MP \#3 & Average & $4.64 \times 10^{-8}$ & $2.79 \times 10^{-2}$ \\
Bio-eth. + ker./Standard & Maximum & $3.39 \times 10^{-6}$ & 6.751 \\
& Average & $3.93 \times 10^{-4}$ & $2.52 \times 10^{-2}$ \\
Bio-eth.+ ker./MP \#3 & Maximum & $3.31 \times 10^{-1}$ & 7.463 \\
& Average & $7.05 \times 10^{-8}$ & $2.52 \times 10^{-2}$ \\
\hline
\end{tabular}

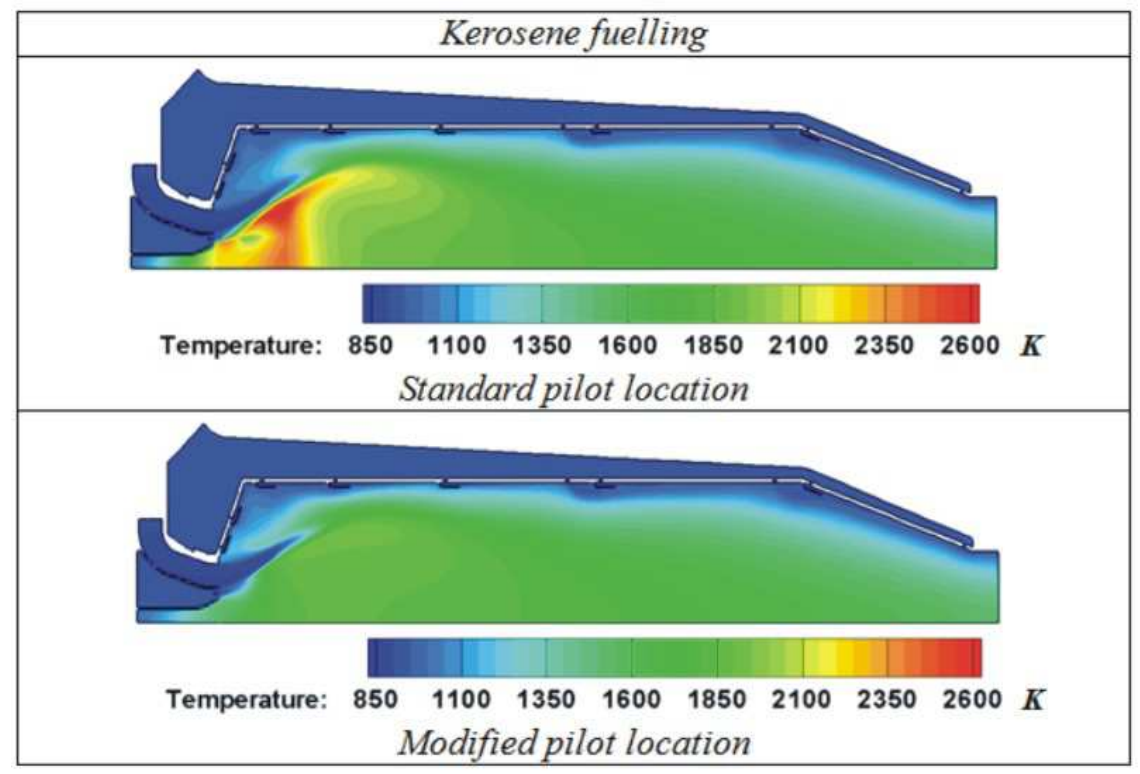

Fig. 8. Temperature distributions for different pilot locations

These results are strictly consequent from the drastic cut-off of the temperature peaks and therefore of the NO formation rates. Conversely, the average fuel oxidation rates do not undergo reductions in the average levels and this preserves an efficient combustion development.
If looking at the comparison between the kerosene and the ethanol supply, the latter fuel exhibits a more favourable response in terms of reduced production of nitric oxides because of the lower flame temperatures. A certain increase can be observed in the unburned species: Despite the UHC amount is still negligible at 
full load operation, more challenging problems could arise at part-load. Such a consideration gives reason of the third option, say the ethanol supply to the leanpremixed line with the kerosene addressed to the pilot injector for aiding the mixture ignition under low fuel/air ratios conditions. The related results generally present intermediate levels between those obtained with the two pure fuels.

The contours in Fig. 8-15 allow detection of the main effects induced by the different pilot locations, together with the basic variations produced by the kind of fuel supplied. When the modified position of the pilot injector is assumed, the high temperature region within the primary zone completely disappears (Fig. 8-10) with a consequent abatement of the nitric oxide formation rates. The extent of this region appears to be significantly smaller with the pure ethanol fuelling and this explains the reduced NO levels that have been already observed in Table 2 and 3. It is also worth-noting that all cases with the new pilot location exhibit a much smoother temperature distribution, so allowing the MILD regime to be fairly approached.

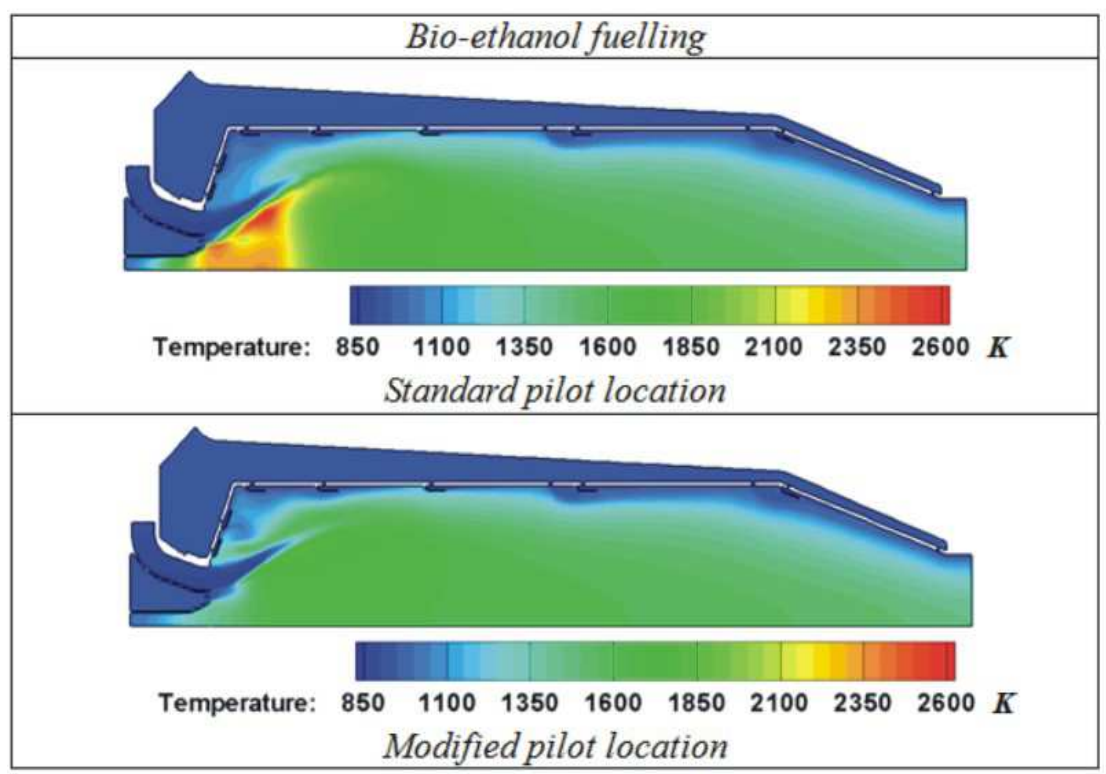

Fig. 9. Temperature distributions for different pilot locations

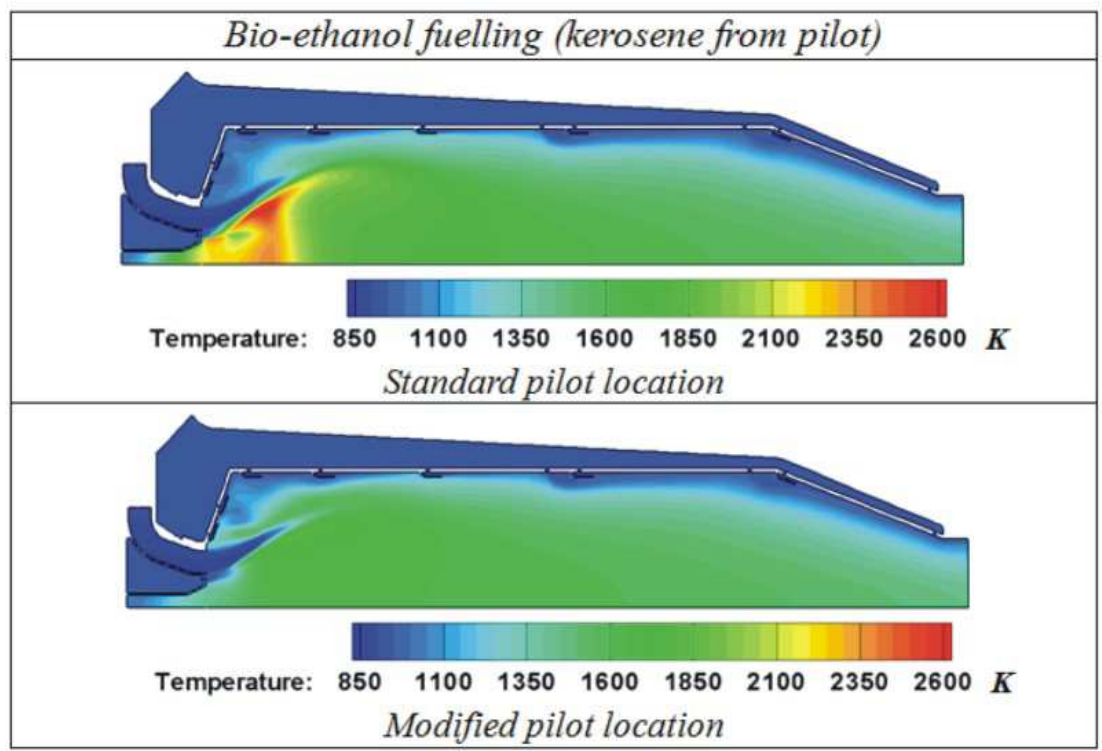

Fig. 10. Temperature distributions for different pilot locations 


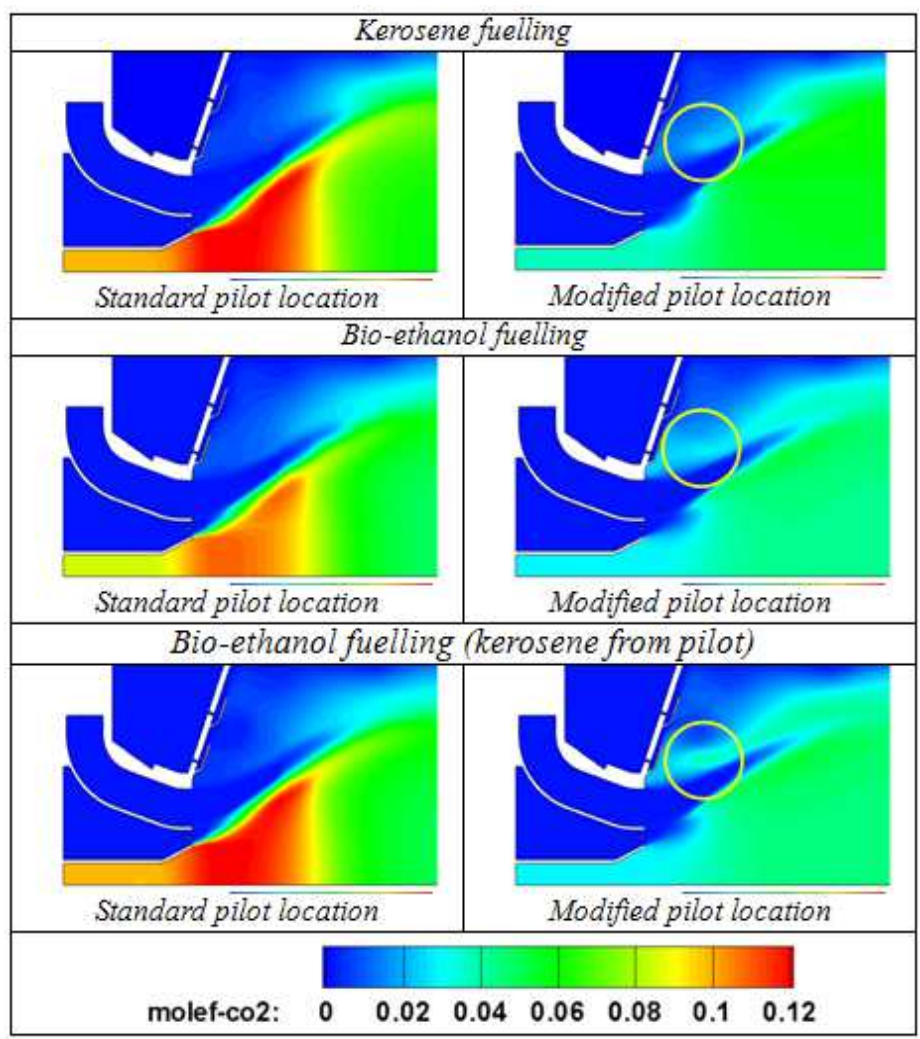

Fig. 11. CO2 distributions for different pilot locations

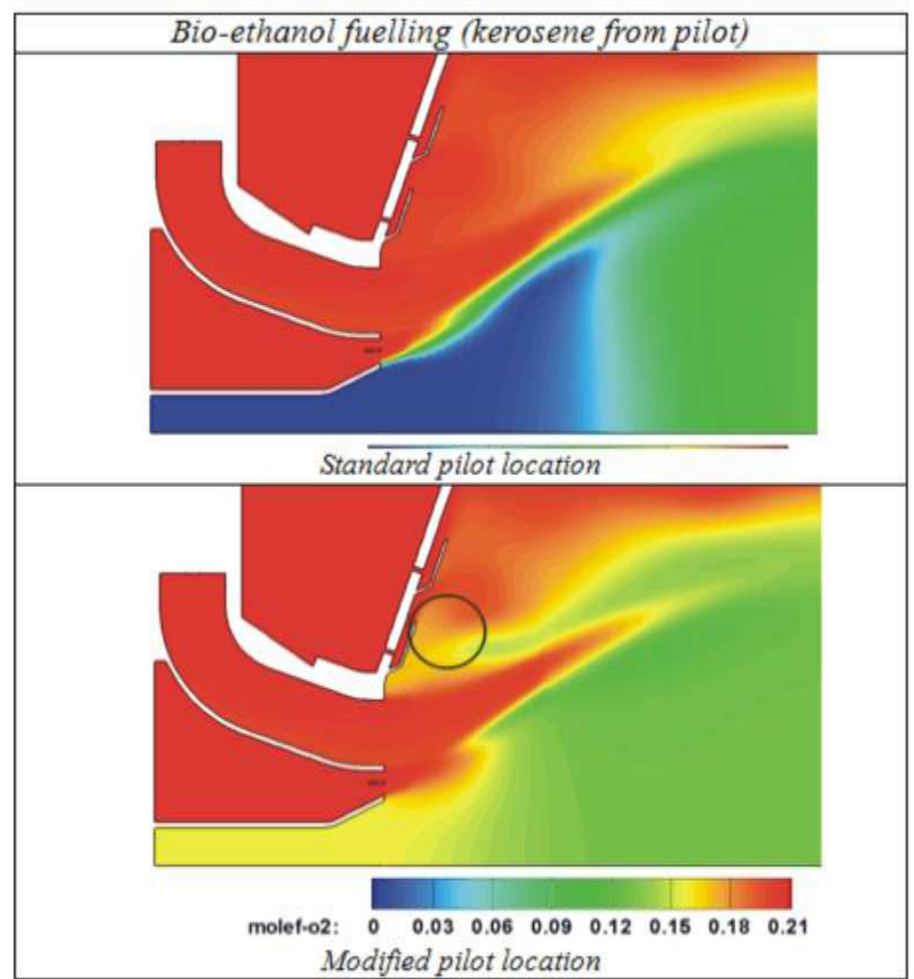

Fig. 12. Oxygen distributions for different pilot locations 


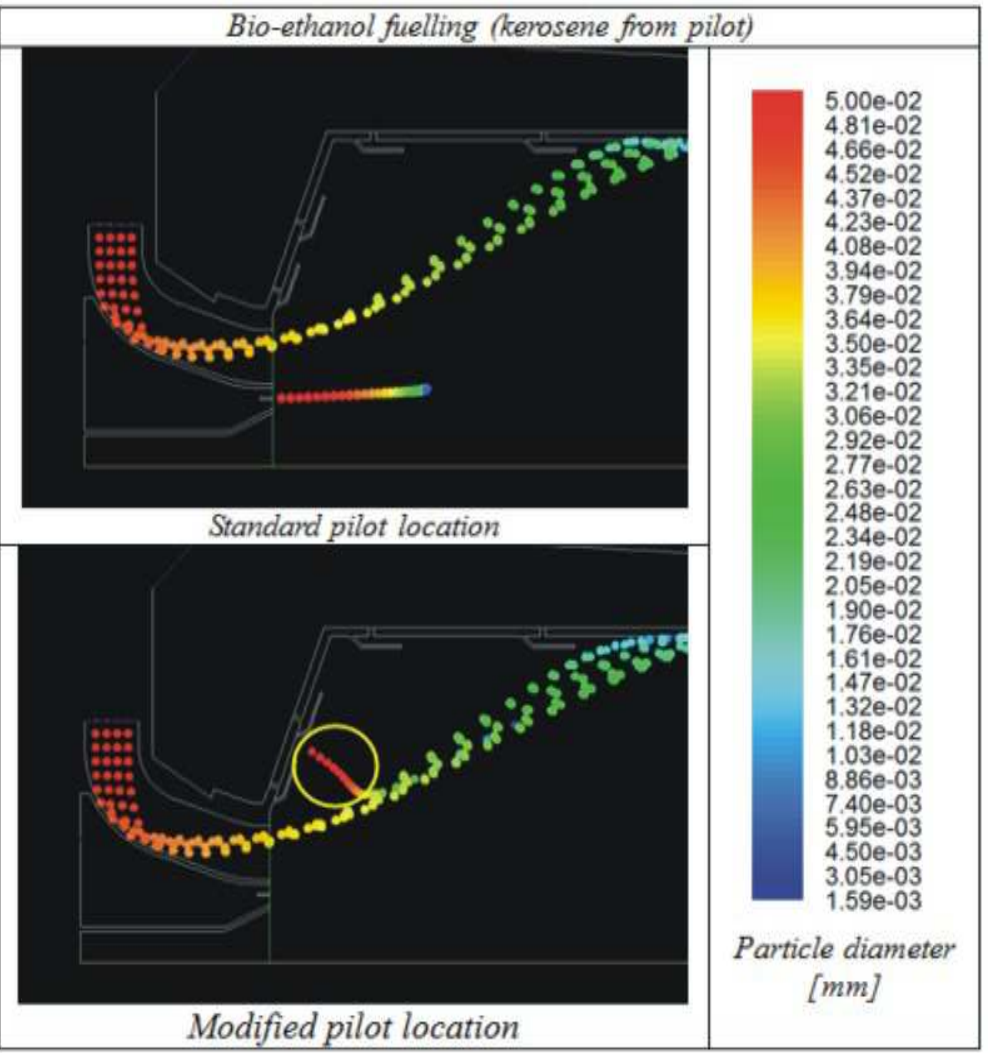

Fig. 13. Liquid particle distribution for different locations of the pilot injector

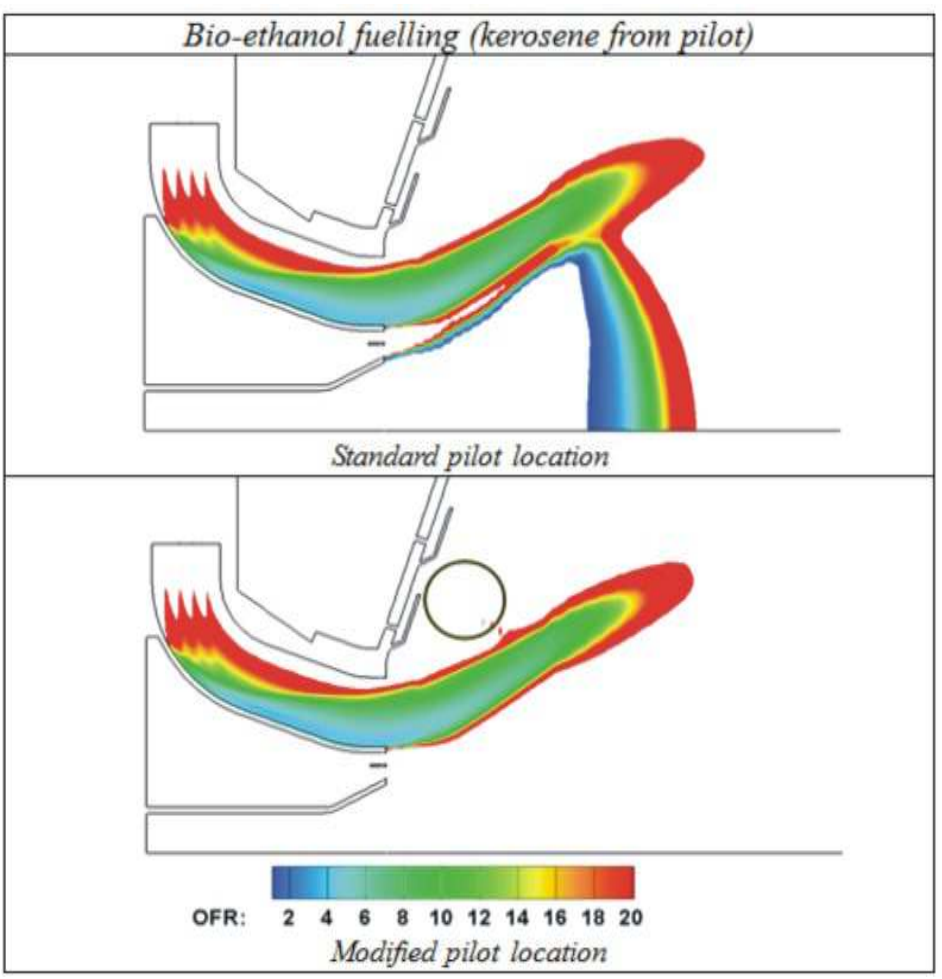

Fig. 14. Oxygen/Fuel Ratio distributions for different pilot locations 


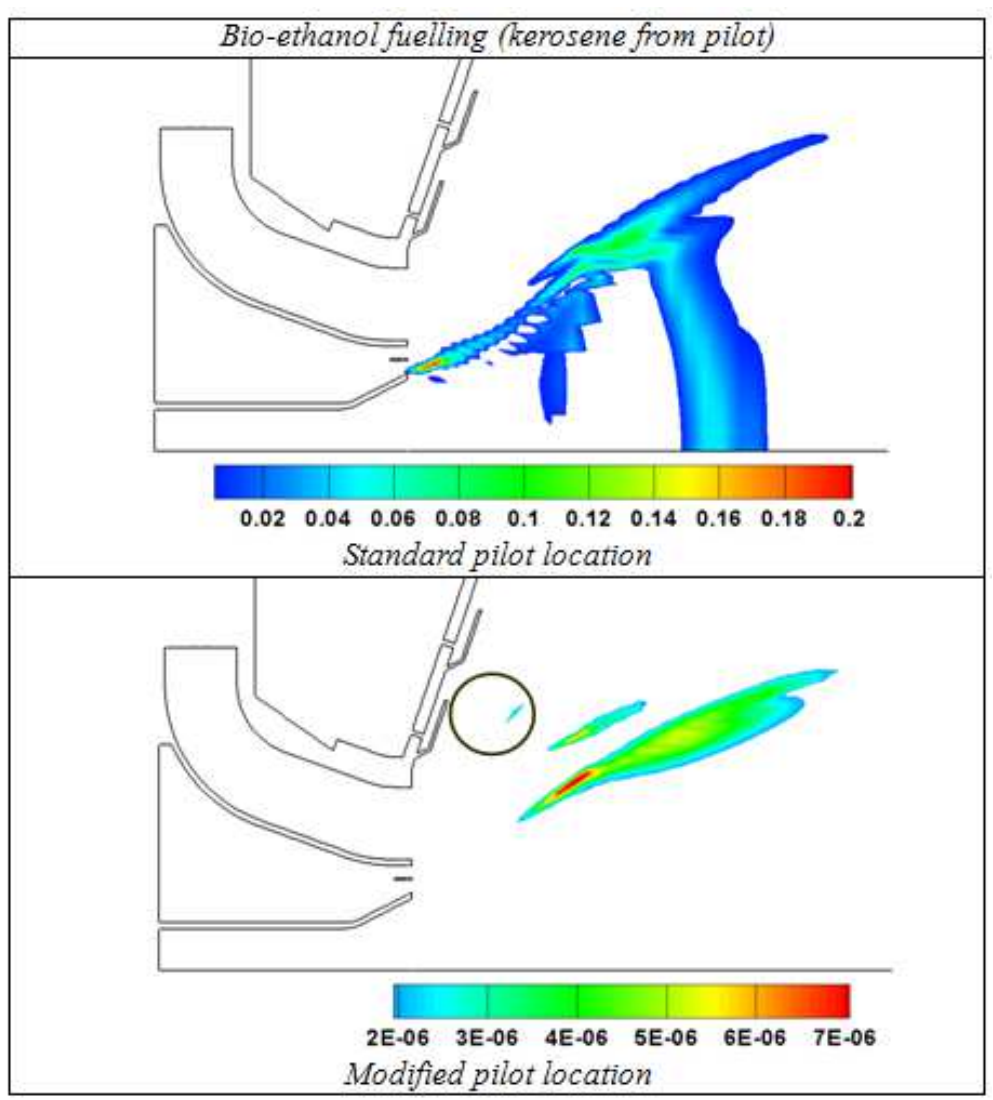

Fig. 15. Thermal + prompt $\mathrm{NO}_{\mathrm{x}}$ formation rates for different pilot locations

A deeper insight to the phenomena that take place within the primary zone of the chamber is helpful for appreciating the real effect of the optimal pilot position. In Fig. 11, the carbon dioxide contours confirm, first of all, that the employment of an ethanol based fuel can contribute to the reduction of the emission of greenhouse gases. Regarding the attempt to realize a nearly flameless combustion, the same figure shows that the pilot jet reaches an area with richer contents in inert species, when the pilot is shifted to the new location. This assertion is confirmed by the fuel jet patterns in Fig. 13 . Similarly, an oxygen defect can be clearly observed within the same area (Fig. 12), so that the conditions for a leaner development of the primary combustion are strictly achieved, like already demonstrated by the temperature distributions in Fig. 8-10.

A further proof of the effects related to the choice of the pilot location can be found in Fig. 13 and 14. The first one displays the different trajectories of the pilot jet and it also demonstrates that the main fuel jet is captured by the primary vortex, as already outlined in Fig. 7. As a consequence, the oxygen/fuel ratio distributions (Fig. 14) result from both the fuel vapour formation and the oxygen presence in the several regions (Fig. 13). The new location addresses the pilot jet in a region of lower
OFR levels, while the stoichiometric region, that exists when the standard location is assumed, disappears.

The most interesting consequence of the variations in property and species distributions discussed above is the drastic reduction in the nitric oxide formation rates (Fig. 15), whose maximum levels are attained in the regions of highest OFRs and where the temperature peaks occur. The decrease by five order of magnitudes is consistent with the one reported in Table 3 and confirms the effectiveness of the proposal for the pilot injector position.

Finally, some axial distributions along a straight line from the lean premixing channel provide an impressive proof of the effect of the pilot shift. The temperature profiles are much more smoother (Fig. 16a) but the level at the combustor outflow remains unchanged, since the fuel oxidation rates undergo only slight variations (Fig. 16b), so preserving a satisfactory combustion efficiency. The temperature peak cut off affects directly the nitric oxide formation rates, like observed in Fig. 15, so that the related molar fraction distributions along the same axial path are significantly reduced (Fig. 16c).

To the sake of a more comprehensive analysis of the actual feasibility of this approach, a CFD simulation in the 3D domain reported in Fig. 6 was carried out. 


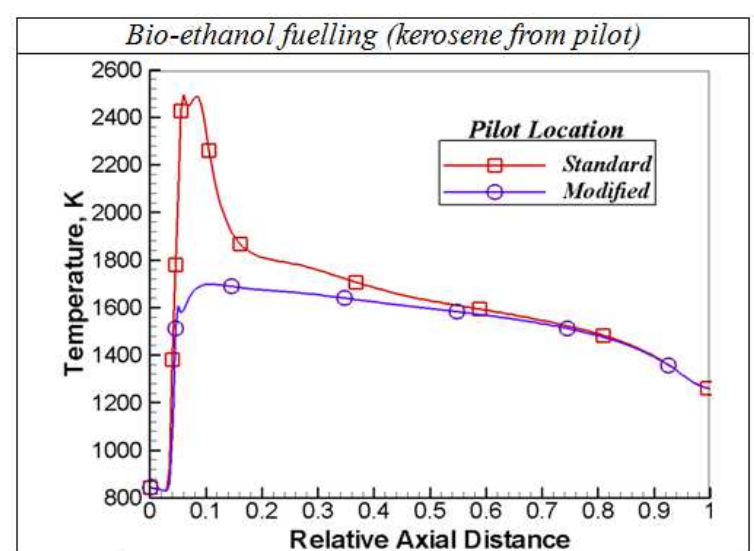

(a)

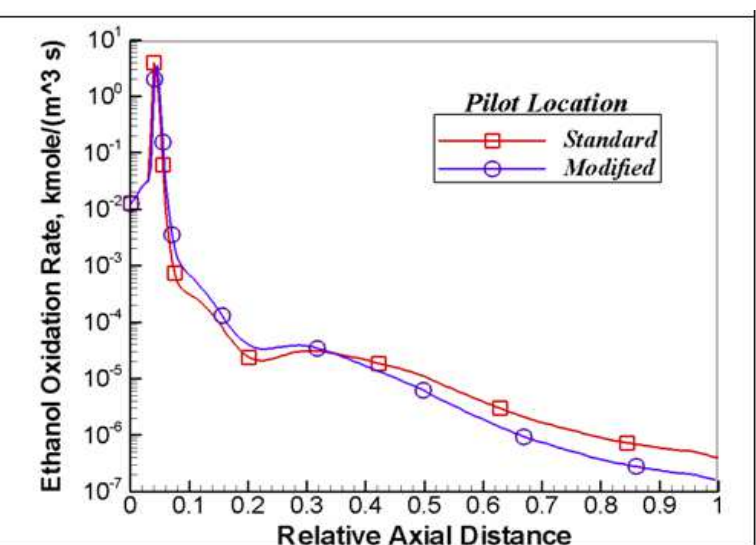

(b)

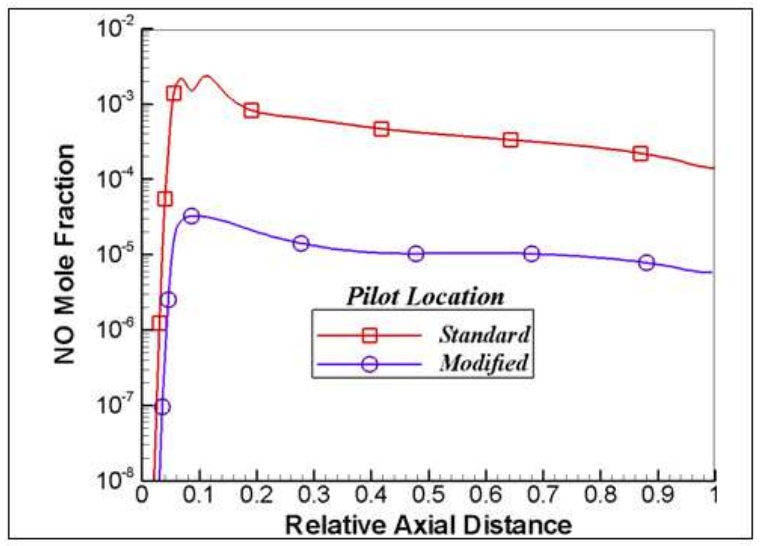

(c)

Fig. 16. Axial distributions of temperature and species

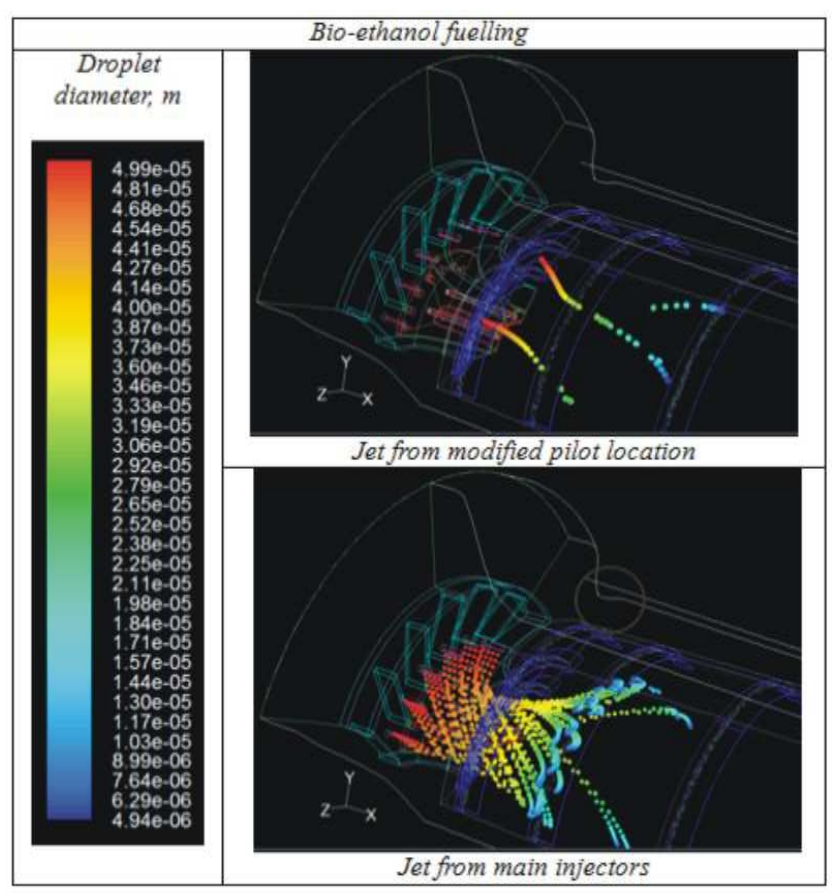

Fig. 17. Droplet distribution in the primary region of the combustor 


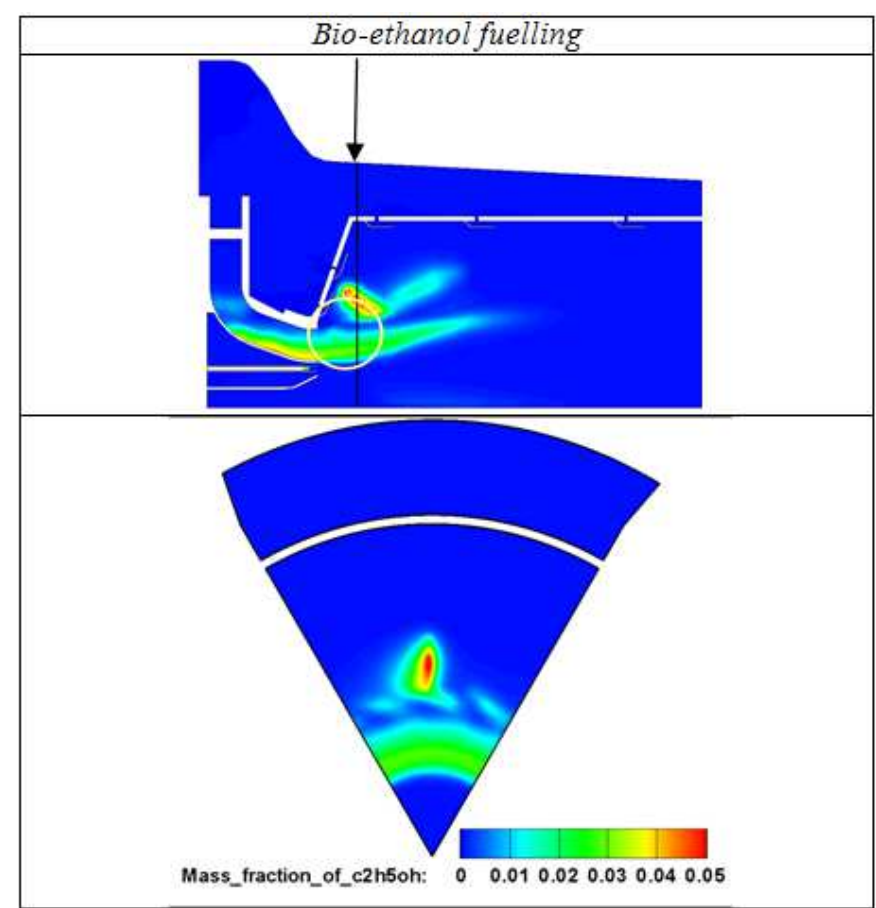

Fig. 18. Contours of ethanol vapour mass fraction in meridional and orthogonal planes

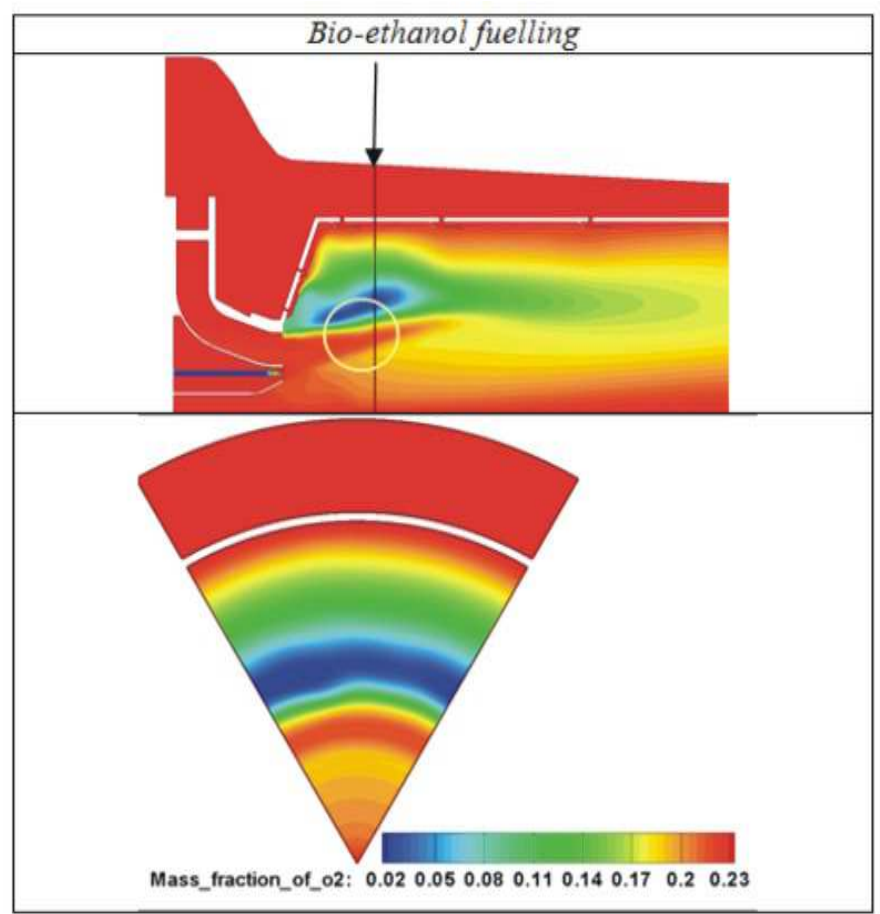

Fig. 19. Contours of oxygen mass fraction in meridional and orthogonal planes

The calculations were performed in a $60^{\circ}$ periodical sector for the case with pure ethanol fuelling with modified pilot location and the results offer a more realistic overview of the spatial distributions of both droplets and flow properties. For example, the droplet trajectories from both pilot and main injectors are clearly influenced by the swirled air motion so that a more intense interaction occurs between the several jets. The droplet diameters that result from the collision and breakup phenomena and from the gas-liquid interaction are reported in Fig. 17. 


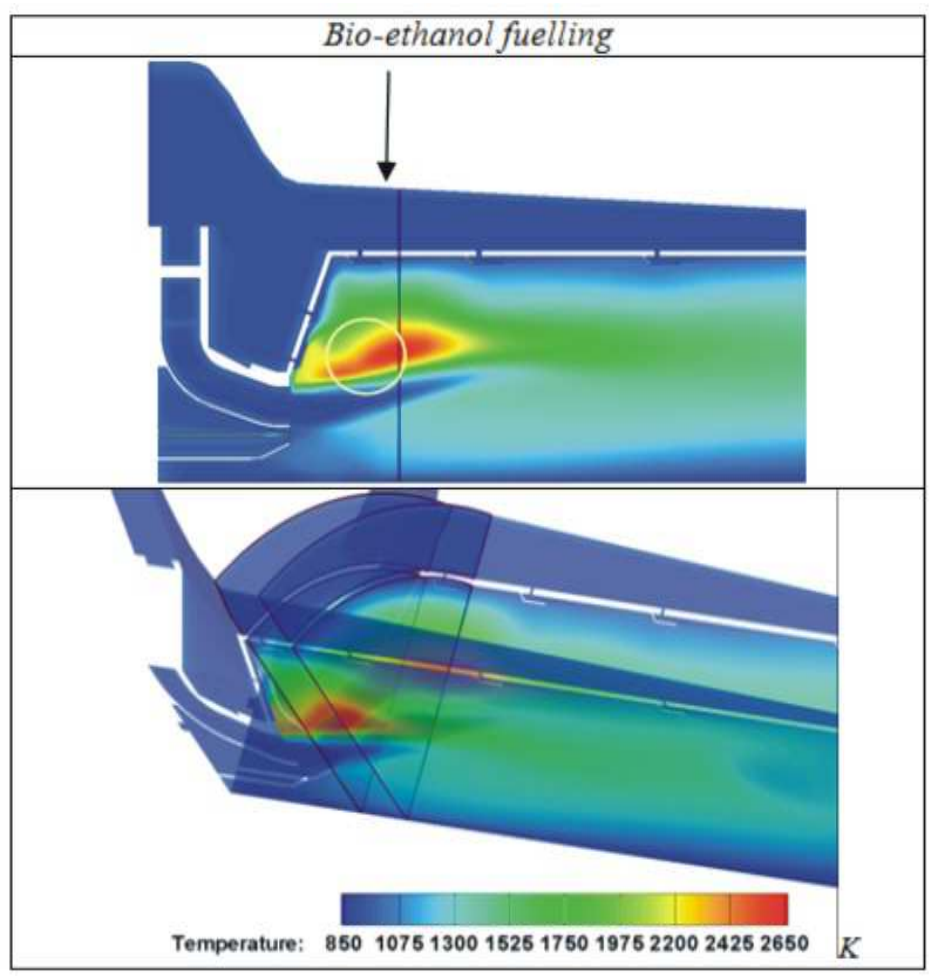

Fig. 20. Temperature contours in meridional plane and in a 3D view

As a consequence of the liquid droplet distribution, the fuel evaporation takes place in the regions highlighted in Fig. 18 both in a meridional and in an orthogonal plane, the latter located just downstream of the pilot injector. This figure shows that the pilot injection role is correctly played since a zone with high fuel vapour concentration can be clearly detected along the pilot line. On the other hand, the contours in the cross section put into evidence that only a limited region is involved in the highest fuel mass fraction. Similarly, the oxygen contours confirm that actually the fuel evaporation takes place in regions with a relevant oxygen lack (Fig. 19). The resulting temperature distributions in Fig. 20, to be compared with those in Fig. 9 for the 2D domain, confirm that a very lean combustion is developing, since the $2000 \mathrm{~K}$ threshold is violated only in very limited regions. At the same time, such diagrams prove that a correct self-ignition is however occurring and the smother fuel oxidation behaviour does not penalize the combustion completion.

\section{Conclusion}

The authors have addressed their work to a comprehensive analysis of the possibilities that are offered by bio-fuel supplying to a micro-gas turbine, together with the attempting of a nearly zero-emission operation.

Regarding to the first aspect, the response of a fuel like ethanol, which can also be found with high concentrations in bio-mass derived fuels, seems to be satisfactory. Actually, the whole combustor process develops correctly without increasing the fuel/air equivalence ratio from the pilot line. Therefore, the results in terms of combustion efficiency are fairly similar to those obtainable with conventional kerosene fuelling. In addition, lower levels of nitric oxides are observed, due to the reduced flame temperatures.

The emission levels can be further decreased by selecting a different location of the pilot injector that addresses the fuel jet to an inert rich region, so allowing the flameless regime to be approached. The latter solution leads to much reduced $\mathrm{NO}_{\mathrm{x}}$ emission by simply exploiting a sort of "internal EGR", so avoiding the activation of the external exhaust recirculation.

The latter method, like already demonstrated by the authors, would be helpful at part-load operation when the intensity of the pilot flame needs to be increased. Also in this case, choosing a modified pilot location will allow operation with reduced rates of the external EGR, so limiting the consequent efficiency decay of the MGT based energy system.

\section{Acknowledgment}

To Ansaldo Ricerche S.p.A. for providing data on the $M G T$ parameters and combustor configuration.

The CFD calculations are licensed by Ansys-Fluent Inc. 


\section{Funding Information}

Funds of the D.I.I. department have financed the research "Internal and External Combustion Systems in Distributed Energy Grids".

\section{Author's Contributions}

All authors have contributed to the development of the whole work. Hereafter is only specified the main role of each other in specific part of the activities.

Maria Cristina Cameretti: Examined different atomization models for the simulation of the droplet pattern.

Raffaele Tuccillo: Organized the different computational tests and the related comments.

Renzo Piazzesi: Set up the computational mesh and experienced different kinetic schemes.

Fabrizio Reale: Carried out the computational cases both of the whole MGT systems and of the combustion chamber.

\section{Ethics}

This article is original and contains unpublished material. The corresponding author confirms that all of the other authors have read and approved the manuscript and no ethical issues involved.

\section{References}

Andrews, G.E., M.N. Kim, M.C. Mkpadi and S.A. Akande, 2007. Liquid fuelled low NOx radial swirlers with central pilot combustion. Am. Society Mechan. Eng., 2: 311-321. DOI: 10.1115/GT2007-27415

Baessler, S., K.G. Mosl and T. Sattelmayer, 2006. $\mathrm{NO}_{\mathrm{x}}$ emissions of a premixed partially vaporized kerosene spray flame. J. Eng. Gas Turbines Power, 129: 695-702. DOI: $10.1115 / 1.2718570$

Bolszo, C., V. McDonell and S. Samuelsen, 2007. Impact of biodiesel on fuel preparation and emissions for a liquid fired gas turbine engine. Am. Society Mechan. Eng., 2: 493-502. DOI: $10.1115 /$ GT2007-27652

Cameretti, M.C. and R. Tuccillo, 2014. Combustion analysis in a micro-gas turbine supplied with bio-fuels. Am. Society Mechan. Eng., 1B: V01BT24A010V01BT24A024. DOI: $10.1115 /$ GT2014-25560

Cameretti, M.C., F. Reale and R. Tuccillo, 2006. Cycle optimization and combustion analysis in a LowN0(x) micro-gas turbine. J. Eng. Gas Turbines Power, 129: 994-1003. DOI: 10.1115/1.2718232

Cameretti, M.C., F. Reale and R. Tuccillo, 2007. $\mathrm{NO}_{\mathrm{x}}$ suppression from a Micro-gas turbine approaching the mild-combustion regime. Am. Society Mechan. Eng., 3: 27-38. DOI: 10.1115/GT2007-27091

Cameretti, M.C., R. Piazzesi, F. Reale and R. Tuccillo, 2008. Combustion simulation of an EGR operated micro-gas turbine. Am. Society Mechan. Eng., 2: 601-610. DOI: $10.1115 /$ GT2008-50692
Cameretti, M.C., R. Piazzesi, F. Reale and R. Tuccillo, 2009. CFD analysis of the flameless combustion in a micro-gas turbine. Am. Society Mechan. Eng., 4: 275-285. DOI: $10.1115 / \mathrm{GT} 2009-59750$

Cameretti, M.C., R. Piazzesi, F. Reale and R. Tuccillo, 2010. Comparison of external and internal EGR concepts for low emission micro gas turbines. Am. Society Mechan. Eng., 4: 275-28.

DOI: $10.1115 /$ GT2009-59750

Cameretti, M.C., R. Tuccillo and R. Piazzesi, 2013. Study of an exhaust gas recirculation equipped micro gas turbine supplied with bio-fuels. Applied Thermal Eng., 59: 162-173. DOI: $10.1016 /$ j.applthermaleng.2013.04.029

Camporeale, S.M. and B. Fortunato, 2007. Thermodynamic analysis of semi-closed gas turbine combined cycles with high temperature diluted air combustion. Am. Society Mechan. Eng., 3: 459-464. DOI: $10.1115 /$ GT2007-28330

Cavaliere, A. and M. de Joannon, 2004. Mild combustion. Progress Energy Combust. Sci., 30: 329-366. DOI: 10.1016/j.pecs.2004.02.003

Crayford, A.P., P.J. Bowen, P.J. Kay and H. Laget, 2010. Comparison of gas-oil and bio-oil spray performance for use in a gas turbine. Am. Society Mechan. Eng., 1: 659-667. DOI: 10.1115/GT2010-23485

Dagaut, P. and T.L. Cong, 2007. Kinetics of natural gas, natural gas/syngas mixtures oxidation and effect of burnt gas recirculation: Experimental and detailed modeling. Am. Society Mechan. Eng., 1: 387-395. DOI: $10.1115 /$ GT2007-27146

Duwig, C., R.Z. Szasz and L. Fuchs, 2006. Modelling of flameless combustion using large eddy simulation. Am. Society Mechan. Eng., 1: 31-40. DOI: $10.1115 /$ GT2006-90063

Glaude, P.A., R. Fournet, R. Bounaceur and M. Molière et al., 2010. Ethanol as an alternative fuel in gas turbines: Combustion and oxidation kinetics. Am. Society Mechan. Eng., 1: 555-562.

DOI: $10.1115 /$ GT2010-22338

Levy, Y., V. Sherbaum and G.A. Rao, 2007a. Preliminary analysis of a new methodology for flameless combustion in gas turbine combustors. Am. Society Mechan. Eng., 2: 577-585. DOI: $10.1115 /$ GT2007-27766

Levy, Y., V. Sherbaum and V. Erenburg, 2007b. The role of the recirculating gases at the mild combustion regime formation. Am. Society Mechan. Eng., 2: 271-278. DOI: $10.1115 /$ GT2007-27369

Levy, Y., V. Sherbaum and V. Erenburg, 2009. Effect of the recirculating gases on the mild combustion regime. Int. J. Turbo Jet-Engines, 26: 9-18. DOI: 10.1515/TJJ.2009.26.1.9

Li, G., E.J. Gutmark, N. Overman and M. Cornwell, 2006. Experimental study of a flameless gas turbine combustor. Am. Society Mechan. Eng., 1: 793-804. DOI: 10.1115/GT2006-91051 
Li, H., M. Altaher and G.E. Andrews, 2010. Evaluation of combustion and emissions using biodiesel and Blends with kerosene in a low NOx gas turbine combustor. Am. Society Mechan. Eng., 1: 545-553. DOI: $10.1115 /$ GT2010-22182

Magnussen, B.F. and B.H. Hjertager, 1977. On mathematical modeling of turbulent combustion with special emphasis on soot formation and combustion. Symp. (Int.) Combust., 16: 719-729. DOI: $10.1016 /$ S0082-0784(77)80366-4

Moliere, M., M. Vierling and R. Symonds, 2010. Interest for liquid fuels in power generation gets renewed. Am. Society Mechan. Eng., 2: 39-46. DOI: $10.1115 /$ GT2010-22149

Moliere, M., M. Vierling, M. Aboujaib, P. Patil and A. Eranki et al., 2009. Gas turbines in alternative fuel applications: Bio-ethanol field test. Am. Society Mechan. Eng., 1: 341-348.

DOI: $10.1115 /$ GT2009-59047
Nakamura, S., V. McDonell and S. Samuelsen, 2006. The effect of liquid-fuel preparation on gas turbine emissions. J. Eng. Gas Turbines Power, 130: 021506-021517. DOI: 10.1115/1.2771564

Panne, T., A. Widenhorn and M. Aigner, 2009. Comparison of combustion models and reaction mechanisms for FLOX ${ }^{\circledR}$ combustion. Am. Society Mechan. Eng., 2: 37-48. DOI: 10.1115/GT2009-59075

Russo, C., J. Parente, G. Mori and V.V. Anissimov, 2007. Micro gas turbine combustor emissions evaluation using the chemical reactor modelling approach. Am. Society Mechan. Eng., 2: 531-542.

DOI: $10.1115 /$ GT2007-27687 